\title{
Havacılıkta Organizasyonel Kazalar: B-737 Max Uçak Kazalarının Mühendislik Perspektifinden İncelenmesi
}

\author{
Tamer Saraçyakupoğlu ${ }^{1}$
}

\section{ÖZ}

Havacılık kazalarının oluşumu çoğunlukla birden fazla nedenden kaynaklanmaktadır. Diğer bir ifade ile havacılık kazaları birçok etkinin birleşiminin bir sonucu olarak meydana gelmektedir. Bu etkilere, üretim süreçleri, bakım faaliyetleri, beşeri unsurlar, meteorolojik şartlar, sertifikasyon kontrolleri ve pist durumu gibi hususlar örnek olarak verilebilir. Diğer taraftan aynı uçak tipindeki ardışık kazalar, doğal olarak dikkat çekicidir. 29 Ekim 2018'de Endonezya'da ve 10 Mart 2019'da Etiyopya'da meydana gelen B-737 Max ticari yolcu uçağı kazaları bu ardışık kazalara örnektir. Bu çalışmada söz konusu kazalar pilotaj ve mühendislik perspektifinden, sertifikasyon süreçleri açısından ele alınmaktadır.

Anahtar Kelimeler: Uçak kazaları, B-737 Max, uçuşa everişlilik, sertifikasyon.

\section{The Organizational Accidents in Aviation: An Investigation of B-737 Max Aircraft Accidents from the Engineering Perspective}

\begin{abstract}
Aviation accidents mostly occur due to more than one reason. In other words, aviation accidents occur as a result of a combination of many effects. Examples of these effects include production processes, maintenance activities, human factors, meteorological conditions, certification controls, and runway condition. On the other hand, consecutive crashes of the same aircraft type are naturally conspicuous. The B-737 Max commercial passenger aircraft crashes that occurred in Indonesia on October 29, 2018, and Ethiopia on March 10, 2019, are examples of these consecutive accidents. In this study, these accidents are discussed from the pilotage and engineering perspective, in terms of certification processes.
\end{abstract}

Keywords: Aircraft accidents, B-737 Max, airworthiness, certification.

\footnotetext{
Geliş/Received $\quad: 23.05 .2020$

Kabul/Accepted : $\quad$ 20.08.2020

1 Dr., İstanbul Gelişim Üniversitesi, Uçak Mühendisliği Bölümü, İstanbul dr.tamer@tamersaracyakupoglu.com.tr Orcid: 0000-0001-5338-726X
} 


\section{EXTENDED ABSTRACT}

\section{Introduction}

On October 29, 2018, a B-737 Max plane crashed into the Java Sea, Indonesia. The aircraft is destroyed and 189 people on board perished. Again, on March 10, 2019, another Boeing B-737 Max crashed in Ethiopia. In the second accident, 159 people lost their lives. These two accidents were one of the most significant aircraft accidents of the International Civil Aviation Organization (ICAO) that was established in 1944 based on the Chicago Convention [1]. ICAO releases regulatory documents such as International Standards and Recommended Practices (SARPs) in terms of aviation safety assurance [3]. But, in many platforms, SARPs are criticized for being regulation-based and considered ineffective especially for the implementation of the novel technologies to the newly designed aircraft types [4,5]. Airworthiness is described as "a written and systematic process documented by the certification authority for the qualification that an aircraft is airworthy under defined operating conditions" [6]. Within the process of the airworthiness there are two phases as "initial" and "continuing" while within the scope of the controls there are "rule-based" and "risk-based" certification activities $[1,7]$.

For a new type, for the airworthiness certification delivery some important requirements provided follow;

- The previous type should be certified,

- Certificate of conformity showing that the aircraft is "convenient for flight" must be completed,

- Weight and balance report should be provided,

- During test flights and physical checks, suitability for flight should be demonstrated $[6,8]$.

A risk-based certification method is a proactive method against the unpredictable effects of the implementation of novel technologies. It is based on the principles as given below;

- Making hazard analysis of new and advanced technology systems applied to aircraft,

- Performing qualification audits by an independent airworthiness body like the "Aviation Safety Institute" apart from Country Airworthiness Authority (CAA),

- Following the possible negative effects of new technologies on aviation through "safety monitoring panels".

For risk-based certification organization Institute of Nuclear Power Operations (INPO) may be an appropriate example from the nuclear industry. INPO is a decision-maker for the validation of newly designed systems in the nuclear field. It provides proactive measures using hypothetical scenarios [9].

\section{Investigation of the Accidents}

Aviation safety has improved in time. For per one million flights; before the 1960's the average number of accidents was 60 while it was decreased to 2,9 in 2019 as ICAO's safety report [10,11].

The phases of flight are the taxi stages before take-off, take-off, climb, cruise, descent, final approach, landing, and after landing as depicted in Figure 1.

The percentages of the accidents are $27 \%$ at the final approach, $20 \%$ at the landing, and $\% 13$ at the take-off.

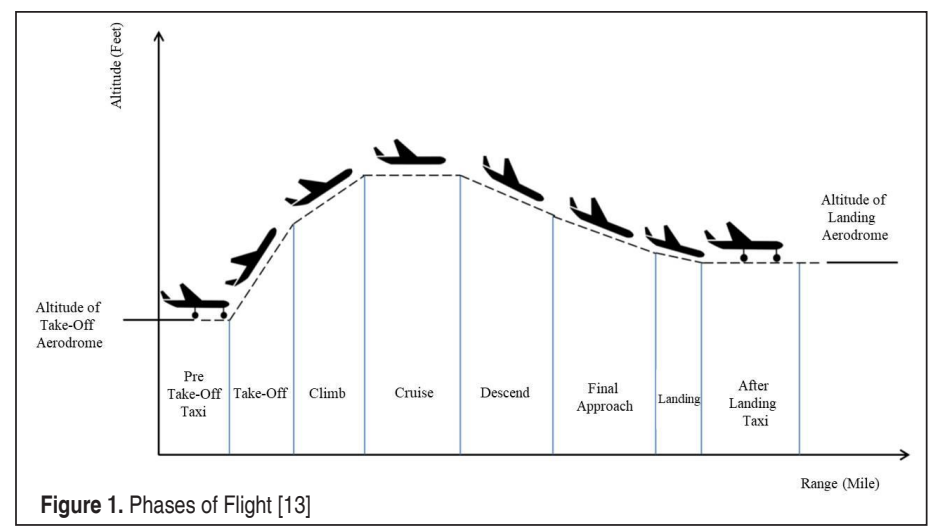

In terms of flight time, the final approach corresponds to approximately $3 \%$ of the total flight time, the landing process to $1 \%$, and the take-off phase to $1 \%$. Meaningly, $60 \%$ of the total aircraft accidents occur in a period of $5 \%$ of the flight time [14]. Both Indonesia and Ethiopia B-727 Max accidents were occurred during take-off and climb phases. 
It would be appropriate to convey the subject of the Angle of Attack (AoA) since it fits on the main axis of the mentioned accidents. As it is shown in Figure 2, the angle between the relative air and the chord line is called as the AoA.

Based on the Flight Data Recorder (FDR) and Cockpit Voice Recorder (CVR) information gained from crash investigation reports of Indonesia and Ethiopia B-737 Max accidents, it is figured out that the cockpit crew struggled with the autopilot that is activated by Maneuvering Characteristics Augmentation System (MCAS) [16,17].

\section{Evaluation and Findings}

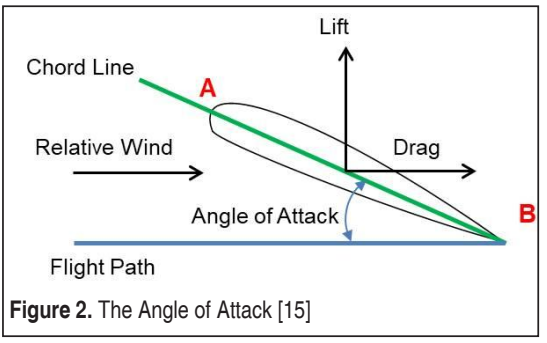

$81 \%$ of the commercial passenger aircraft were manufactured by either Boeing or by its competitor Airbus. This market-share naturally brings fierce competition between them. For not falling behind the other, when one creates a new type, the other responds with the newer [21]. When Airbus A-320 Neo was created with the bigger engines known with fuel efficiency, Boeing had to design a new type for meeting the market requirements. At that time, B-737 NG was the strongest candidate can be equipped with larger engines similar to used on A-320 Neo. But the problem was B-737 NG's distance clear is/was too short for the bigger engines.

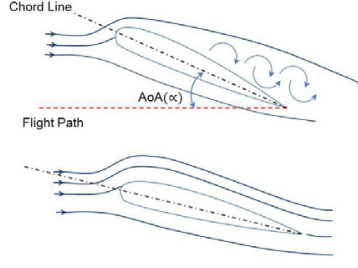

Figure 3. AoA and Stall

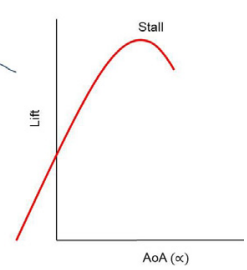

$A \circ A(\alpha)$

Re-positioning the bigger engines to the further forward and higher up on the wings was considered a solution. This solution triggered a high AoA tendency. The stall is a loss of lift of the wing bases on very low speed or to exceeding the critical AoA. There's a correlation between AoA and stall as demonstrated in Figure 3.

Eventually, B-737 Max was manufactured equipped with larger engines than its immediate predecessor B-737 NG [25]. And as mentioned before, "engine re-positioning" has brought the pitch-up tendency and vertical instability phenomena that force the aircraft to stall. MCAS, that is a software-based solution used for stabilizing force as shown in Figure 4.

It's figured out from investigation reports, that the cockpit crew couldn't achieve the re-gain the control of the aircraft [27]. The Allied Pilots Association (APA) has announced the probable reason. Pilots were unaware of MCAS's adverse effects due to a lack of training [29].

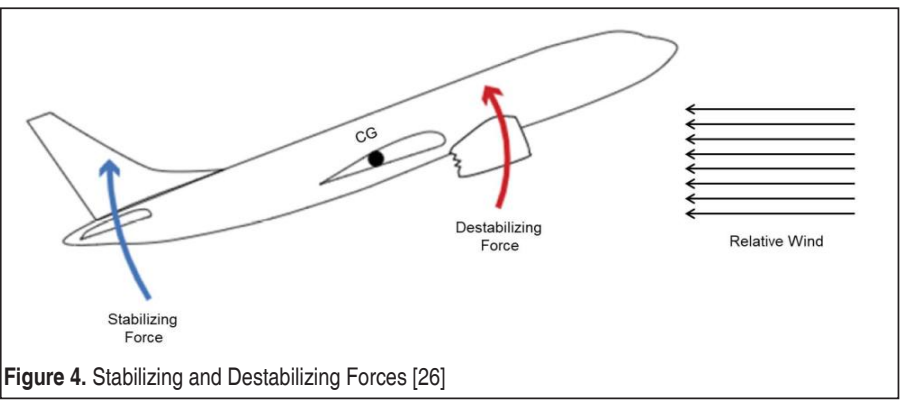

\section{Conclusion}

- Designated Engineering Representatives (DER) should be used non-critical system implementations.

- Airworthiness certification/re-certification for new types should be executed by the CAA staff.

- In pursuit of aviation engineering, MCAS should be fed by the verification of at least two sensors as Airbus does. In Airbus Flight Crew Operational Manual (FCOM), it is written that "High AOA protection is more important than any other". The same philosophy should be applied for B-737Max and other types.

- After the implementation of the critical system to the aircraft, the crew should be trained considering the risk impact of the system.

- A risk-based certification process should be used instead of a regulatory-based one. 


\section{GİRIŞ}

29 Ekim 2018 tarihinde Endonezya'da bir Boeing B-737 Max uçağı düşmüş ve 189 kişinin hayatını kaybetmesine yol açmıştır. Aradan yaklaşık 4 aylık bir zaman geçtikten sonra, 10 Mart 2019'da yine bir B-737 Max uçağı bu kez Etiyopya'da düşmüş, bu kazada da 157 kişi hayatını kaybetmiştir.

Toplam can kaybının 346 kişi olduğu, B-737 Max kazaları, Aralık 1944'te Chicago Konvansiyonu ile kurulan Uluslararası Sivil Havac1lık Organizasyonu'nun (USHO, International Civil Aviation Organization-ICAO) tarihindeki en dikkat çekici kazalar arasında yer almaktadır [1].

ICAO Birleşmiş Milletler'e bağlı, havacılık otoritelerinin en tepesindeki organizasyondur ve Birleşmiş Milletler' in en başarılı alt organizasyonlarından birisi olarak kabul edilmektedir [2]. ICAO, havacılık kurallarına bağlı olarak uçuş ve yer emniyetini arttırmak amacıyla uluslararası standartlar ve uygulamalara yönelik önemli dokümanlar yayımlamaktadır. Bu dokümanlar içerisinde en önemlilerinden bir tanesi "Uluslararası Standart ve Önerilen Pratikler" (International Standards and Recommended Practices-SARP) standartlarıdır. Bahse konu dokümanların ilgili kurum ve kuruluşlara dağıtılmasındaki amaç, gün geçtikçe büyüyen ve çok katmanlı bir disiplin haline gelen havacılığı küresel seviyede olabildiğince emniyetli hale getirmeye çalışmaktır [3]. Ancak birçok platformda SARP gibi uygulamaların, yeni teknolojilerin uçaklara uyarlanmasında yetersiz kaldığına ve söz konusu uygulamaların dijital tabanlı yapılmasına yönelik görüşler bulunmaktadır [4]. Bu görüşlerin temelinde, özellikle yeni sistemlerin hava taşıtlarına uyarlanmasında kural tabanlı sertifikasyon sürecinden, risk tabanlı sertifikasyon sürecine geçiş ve dijital eksenli uygulamaların hayata geçirilmesi yer almaktadır. Keza, yine aynı organizasyonun farklı birimlerinde havacılık otoritelerinin emniyet gözetim sürat ve yeteneklerinin, uçaklara uyarlanan yeni teknolojileri denetlemede yetersiz kalabilecekleri ve bu durumun uçuş ile yer emniyetine yönelik bir risk olarak ifade edilmektedir [5].

Bu safhada, uçuşa elverişlilik kavramı üzerinde durulması uygun olacaktır. Tanım itibariyle uçuşa elverişlilik, bir hava aracının ömür devri boyunca, belirli bir konfigürasyonda kullanım ve limitlendirmelerle, uçuş mürettebatı, yer ekibi, yolcu, diğer hava araçları ve üstünde uçtuğu meskûn mahal için kabul edilenlerin dişında bir risk yaratmadan uçuşunu emniyetle başlatabilme, sürdürebilme ve sonlandırabilme yeteneğidir. Uçuşa elverişlilik sertifikasyonu ise tanımlanmış operasyon şartlarında bir hava aracının uçuşa elverişli olduğunun belirlenmesi için uygulanan ve sertifikasyon otoritesi tarafından belgelenmiş sistematik bir süreçtir [6]. Uçuşa elverişlilik sertifikasyonu, "başlangıç" ve "sürekli uçuşa elverişlilik" olarak iki farklı süreçte ele alınmaktadır.

Genel itibariyle, yapılan kontroller kapsamında sertifikasyon süreci, "kural tabanlı" ve "risk tabanlı" olmak üzere iki farklı cephede ele alınabilmektedir [1,7]. 
Kural tabanlı sertifikasyon süreci, hava aracının üretildiği ülkenin havacılık otoritesi tarafindan belirlenen yönergeler çerçevesinde alışılmış olarak devam eden yöntemleri içermektedir. Bu süreçte, özellikle bir hava aracı tipinden geliştirilen bir başka tipe yönelik fark kontrol listeleri uygulanmaktadır. Örnek olarak,

B-737 Max uçağı, bir önceki tip olan B-737 NG baz alınarak geliştirilmiştir. Bu nedenle kontrol listelerinde, her iki tipin farklılıkları üzerinde durulmaktadır.

Bir hava aracı tipi/modelinden geliştirilen hava aracına "Uçuşa Elverişlilik Sertifikas1" verilebilmesi için;

- Önceki tip için bir hava aracı tip sertifikasının mevcut olması,

- Hava aracının uçuş için uygun durumda olduğunu gösteren uygunluk belgesinin tamamlanmış olması,

- Hava aracının ağırlık ve denge raporunun hazır olması,

- Yapılacak test uçuşlarında ve fiziki kontrollerde hava aracının uçuş için uygun durumda olduğunun belirlenmesi gibi şartlar söz konusudur [6,8].

Risk tabanlı sertifikasyon süreci ise hava araçlarında kullanılan yenilikçi teknolojilerin meydana getirebileceği tehlikeleri ön gören ve buna yönelik tedbirler geliştiren önalıcı yaklaşımdır. Risk tabanlı sertifikasyon sürecinde;

- Hava araçlarına uygulanan yeni ve ileri teknoloji sistemlerinin tehlike analizleri yapilmas1,

- Ülkelerin devlet havacılık otoritelerinin dışında Havacılık Emniyeti Enstitüsü benzeri bağımsız bir yapı tarafından denetlemeler gerçekleştirilmesi,

- Emniyet izleme panelleri ile yeni teknolojilerin havacılığa olabilecek olumsuz etkilerinin takip edilmesi gibi faaliyetler söz konusudur.

Günümüz dünyasında, havacılık sektöründe olmasa da, risk tabanlı sertifikasyon denetlemeleri gerçekleştiren, bağımsız, söz sahibi olan kurumlar mevcuttur. Üretim fazında ve operasyonel aşamada azami hassasiyet gerektiren nükleer enerji teknolojileri kullanan tesislerin yeterliliklerinin ölçülmesinde risk tabanlı değerlendirmeler yapılmaktadır. Merkezi ABD Atlanta'da bulunan Nükleer Güç Operasyonları Enstitüsü (NGOE, Institute of Nuclear Power Operations-INPO) bu tarz yapılanmaya bir örnektir. INPO, nükleer alanda yeni tasarlanan sistemlerin validasyonu konusunda karar vericidir. INPO, varsayımsal senaryolar geliştirerek güvenlik açısından kritik sistemlere yönelik önalıcı tedbirleri sağlamaktadır [9].

\section{UÇAK KAZALARININ İNCELENMESI}

Bilgisayarla yönetilen sistemlerin hayata geçirilmesi ve gelişen teknolojinin havacılığa hızla uyarlanması sonucu gün geçtikçe daha karmaşık bir mimari kullanımı söz konusu olmuştur. Mevcut durumda, bir modern yolcu uçağında birbirinden farklı 
sistemleri kontrol altında tutan yüzlerce bilgisayar senkron halde çalışmaktadır. $\mathrm{Bu}$ durum uçuş ve yer emniyetine olumlu katkı sağlamaktadır. Havacılık alanında yapılan mühendislik ve emniyet yönetim çalışmalarının sonucunda kaza oranları 1960'l1 yıllardan günümüze kadar büyük oranda azaltılmıştır. 1960'lı yıllardan önce bir milyon uçuşta yaklaşık 60 kazanın meydana geldiği gözlemlenmiştir [10]. ICAO'nun 2019 yılı uçak kaza verilerine göre bu sayı bir milyon uçuşta 2,6 seviyesine inmiştir [11]. ICAO Annex 13 dokümanına göre hazırlanan söz konusu veriler, azami kalkış ağırlığı (AKA, Maximum Take-Off Weight-MTOW) 5700 kg’ın üzerindeki tarifeli ticari uçuşlar için geçerlidir [12].

\subsection{Uçuş Safhaları ve Hücum Açısı}

Şekil 1'de görüldüğü üzere bir uçuş süreci ana hatları ile kalkış öncesi taksi, kalkış, tırmanış, seyir, alçalış, son yaklaşma, iniş ve iniş sonrası taksi evrelerinden oluşmaktadır.

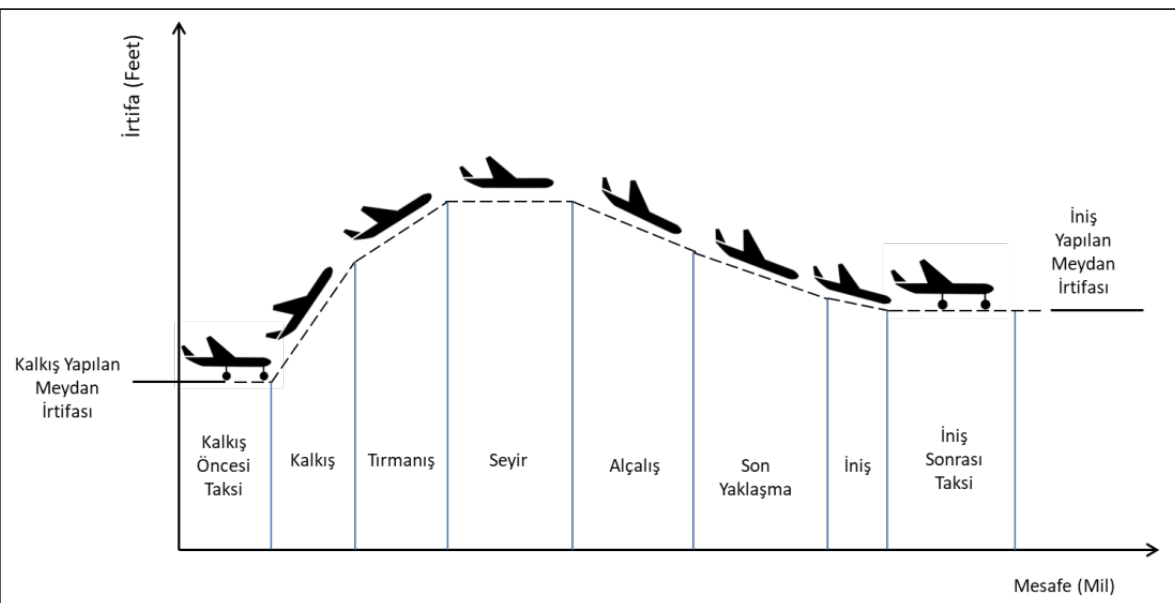

Şekil 1. Uçuş Safhaları [13]

Yapılan istatistiksel çalışmalara göre kazaların \%27'si son yaklaşmada, \%20'lik kısmı ise inişte gerçekleşmektedir. Kalkışta gerçekleşen kaza oranı ise \%13'tür. Zaman olarak ele alındığında, son yaklaşma toplam uçuş zamanının yaklaşık \%3'üne, iniş süreci \%1'ine, kalkış periyodu ise yine \%1'ine karş1lık gelmektedir. Sonuçta uçak kazalarının \%60’lık bölümü kalkış, son yaklaşma ve iniş safhalarında gerçekleşmektedir [14]. Diğer bir ifade ile toplam uçak kazalarının \%60'lık bölümü, uçuş zamanının \% $\%$ 'lik bir periyodunda gerçekleşmektedir.

Bu verilere uygun olarak, Endonezya ve Etiyopya' da gerçekleşen kazalar, riskli kabul edilen kalkış ve tırmanış süreçlerinin içerisinde gerçekleşmiştir. 


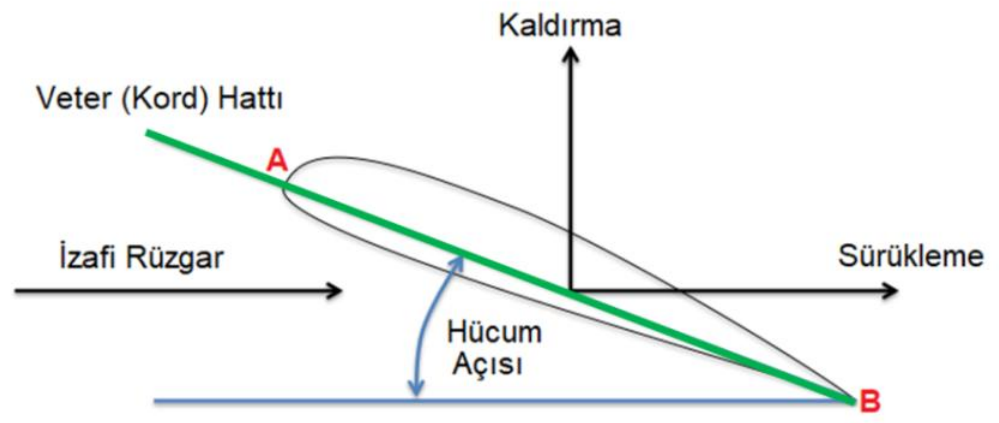

Şekil 2. Hücum Açısı (HA, Angle of Attack-AoA ) [15].

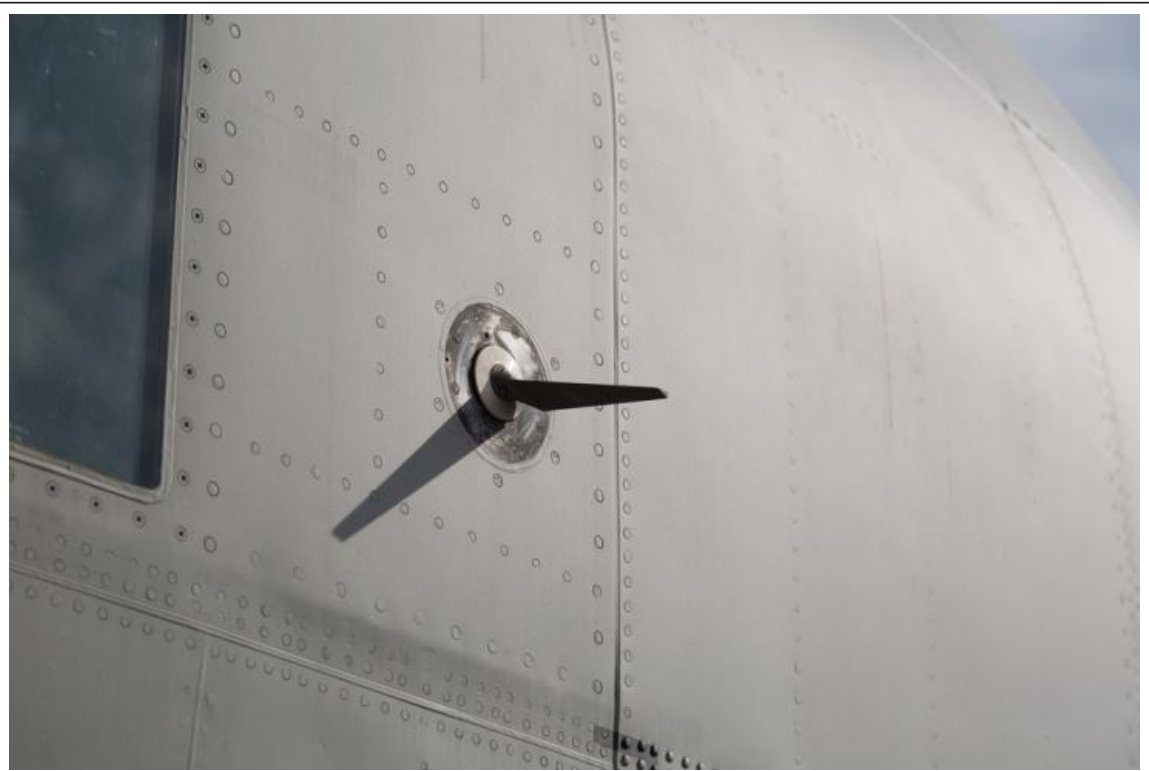

Şekil 3. Uçağın Her Iki Tarafında Bulunan AoA Sensörü

Söz konusu kazalarda ana eksene oturduğu için, Hücum Açısı (HA, Angle of AttackAoA ) konusunun aktarılması uygun olacaktır.

Şekil 2'de görüldüğü üzere, bir kanat profili üzerinde A bölgesi "hücum kenarı" ve B bölgesi "firar kenarı" olarak isimlendirilmektedir. A noktasından B noktasına uzanan doğruya ise veter ya da kord hattı adı verilmektedir. Kanadın karşıladığı izafi hava akışı ile veter hattı arasındaki açı Hücum Açısı olarak isimlendirilmektedir.

Uçağın en iyi tırmanma açısı, en iyi tırmanma sürati gibi uçuş performansını belir- 
leyen karakteristiklerin değerlendirilmesi amacıyla son derece önemli olan hücum açısının derecesi, Şekil 3'te uçak üzerinde gösterilen sensörler tarafından algılanmaktadir.

\subsection{B-737 Max Endonezya Kazasının Oluşum Şekli ve Karakutu Çözümlemeleri}

29 Ekim 2018 tarihinde, Endonezya Lion Air Havayollarına ait 610 sefer sayılı PKLQP çağrı kodlu B-737 Max uçağı, başkent Jakarta' daki Soekarno-Hatta Uluslararası havaalanından, Pangkal Pinang Depati Amir havaalanına tarifeli uçuşunu gerçekleştirirken, yerel saatle sabah 06.32 sularında, kalkıştan yaklaşık 13 dakika sonra Java Denizi'ne düşmüştür. Kaza, Eşgüdümlü Evrensel Zaman (UTC) ile 23.32 sıralarında gerçekleşmiştir. Uçakta aralarında görevli uçuş mühendisinin de bulunduğu 181 yolcu, 2 pilot ve 6 kabin memur olmak üzere toplam 189 kişi hayatını kaybetmiştir. Enkaz arama-kurtarma çalışmaları sırasında bir emniyet dalgıcının da hayatını kaybetmesi nedeniyle, toplam can kaybı 190 olarak açıklanmıştır. Kaza-kırım raporundan, kaptan pilotun 6028 saat ve ikinci pilotun ise 5174 saat uçuş tecrübesine sahip olduğu bilgisi edinilmektedir. PK-LQP çağrı kodlu uçağın ise toplam 893 saat 21 dakikalık uçuş zamanı mevcuttur. Uçağın bakım dokümanlarında görüldüğü üzere yardımcı batarya, sigortalar vb. konularda arızalar gerçekleşmiş ve ilgili bakım personelleri tarafından söz konusu arızalar giderilmiştir. Meteorolojik değerlendirmede, kazanın olduğu gün, Jakarta'daki Soekarno-Hatta Uluslararası Havaalanı, Pangkal Pinang Depati Amir Havaalanı ve seyrüsefer rotası boyunca şartların, uçağın konfigürasyon limitleri dâhilinde olduğu görülmektedir.

Kazanın Uçuş Veri Kaydedicisi (UVK, Flight Data Recorder-FDR) ve Kokpit Ses Kaydedicisi (KSK, Cockpit Voice Recorder-CVR) sistemlerinden oluşan karakutusu üzerinde yapılan çalışma neticesinde kalkıştan, düşme anına kadar kritik safhalar UTC zamanına göre aşağıda sunulmaktadır:

- 23.19.02: Hava Trafik Kontrol (HTK, Air Traffic Control-ATC) / kuleden kalkış için müsaade istenmiş, uçak pistte koşmaya başlamış ve kalkış süratine ulaşılmasına müteakip (VRotate) 23.20.33'te havalanmıştır.

- 23:21:22: Kule uçağa 27.000 feet'e tırmanması için müsaade verildiğini bildirmiştir.

- 23.21.28: İkinci pilot kuleye mevcut radar irtifasını sormuş ve 900 feet yanıtını almıştır.

- 23.22.00: Flapların nötr duruma getirilmesinden, saniyeler sonra Manevra Karakteristiği Güçlendirme Sistemi (MKGS, Maneuvering Characteristics Augmentation System-MCAS) devreye girmiş ve uçağa burun aşağı kumandası vermiştir. 
- 23.24.11: Kaptan hava sürati göstergesinin güvenilir işar vermediğini ikinci pilota bildirmiştir. CVR'da yer alan bu konuşma FDR' da yer alan irtifa dalgalanması ile örtüşmektedir.

- 23.25.11: İkinci pilot kuleye güvenilir bir hava sürati verisi alamadıklarını deklare etmiştir. Bu süre zarfında uçak burnunun dikey vektörde sürekli aşağı yukarı hareket ettiği gözlemlenmektedir.

- 23.28.09: Bir kabin memuru kokpite çağırılmıştır.

- 23.28.18: Kaptan kabin memurundan uçuş mühendisinin kokpite getirilmesini istemiştir.

- 23.29.41: İkinci pilot kuleye uçağı elle kumanda ettiklerini deklare etmiştir.

- 23.30.02: Uçağın kumandasına yönelik sorun yaşandığını bildirmiştir. Kule kalktıkları piste geri inmeleri için 070 (Kuzey-Kuzeydoğu) başına dönmelerini talep etmiştir.

- 23.31.08: Kaptan kuleye gösterge panelindeki işarların farklılığg nedeniyle uçak irtifasının net olarak belirlenemediğini bildirmiştir. Bu esnada uçağın 5000 feet irtifadan derin bir dalış açısıyla burun aşağı verdiği görülmektedir.

- 23.31.33: İkinci pilot bağırarak uçağın düşmekte olduğunu bildirmiştir.

- 23.31.51: Yer Yaklaşım İkaz Sistemi (YYİS, Enhanced Ground Proximity Warning System-EGPWS) yere aşırı yaklaşıldığına dair “Terrain” ikazı vermiştir.

- 23.32.20: PK-LQP çağrı kodlu B-737 Max uçağı radardan kaybolmuştur.

Uçuşun genel seyrinde oto-pilot ve pilotların karşılıklı kumandalarına yönelik hususlar aşağıda sunulmaktadır:

- 23.19.02'den düşme zamanı olan 23.32.12'ye kadar uçağın AoA sensörleri arasındaki 210'lik fark hiç değişmemiştir.

- Uçuş sırasında oto-pilota bağlanıldığına dair işar alınmamıştır.

- 23.22.00'de flapların nötr duruma getirilmesinin hemen ardından kaptan ve ikinci pilot kontrolü almak için müdahalede bulunmuşlar, MCAS ve kokpit mürettebatı arasındaki mücadele düşme anına kadar devam etmiştir.

- Uçuş müddetince düzeltilmiş hava sürati (Computed Airspeed) ve irtifa parametreleri sağ ve sol sensörler açısından farklılık göstermektedir.

- Yaklaşık 13 dakika süren toplam uçuş zamanının çoğunda kaydedilen irtifa 5.000 feet civarında dalgalanmış ve sabit bir irtifa değerine yerleşmemiştir.

- Kalkışa müteakip sol lövye (Yoke) titreşimi etkinleşmiş, UTC 23.22 sıralarında, 
yani kalkıştan yaklaşık 2 dakika gibi çok kısa bir zaman aralığında durmuştur. Durduktan yaklaşık 15 saniye sonra tekrar harekete geçmiş ve uçak denize düşene kadar durmamıştır [16].

\subsection{B-737 Max Etiyopya Kazasının Oluşum Şekli ve Kara Kutu Çözümlemeleri}

13 Mart 2019 tarihinde, Etiyopya Havayollarına ait 302 sefer sayılı, ET-AWJ çağrı kodlu B-737 Max uçağı, Addis Ababa Bole Uluslararası Havaalanı'ndan, Kenya Nariobi Jomo Kenyatta Havaalanı'na tarifeli uçuşunu gerçekleştirirken UTC saatine göre 05.44, yerel saatle 08.44 sularında, kalkıştan yaklaşık 5 dakika sonra düşmüştür. Kazada 149 yolcu ve 8 mürettebat olmak üzere toplam 157 kişi hayatını kaybetmiştir. Kaza-kırım raporundan, kaptan pilotun yaklaşık 8122 ve ikinci pilotun ise yaklaşık 361 saatlik uçuşlarının olduğu anlaşılmaktadır. Uçuş mürettebatının kabinde yer alan ekibi olarak, 5 kadın kabin personeli ve 1 uçuş emniyet memurunun (Inflight Security Officer-IFSO) uçakta görev aldığı bilinmektedir. Uçak, kaza anına kadar 1330,8 saat uçuş yapmıştır. Uçağın bakım dokümanlarından, planlı bakımlarının zamanında yapıldığı görülmektedir. Arıza bulguları kapsamında, kaza anına kadar gerçekleşen 39 sortilik uçuş sürecinde sadece bilgisayar çıkışında güç bulunmaması, düşük basınç nedeniyle mürettebat oksijen silindirinin değiştirilmesi ve Yardımcı Güç Ünitesinin (YGÜ, Auxiliary Power Unit-APU) çalışmaması durumlarının söz konusu olduğu, her üç arızanın da giderildiği ve tekerrür etmediği belirlenmiştir. Meteorolojik değerlendirmede, kazanın olduğu gün Etiyopya Addis Ababa ve Kenya Nariobi Jomo Kenyatta Havaalanları ve seyir rotası boyunca meteorolojik şartların uçak limitleri dâhilinde olduğu görülmektedir. Uçağın karakutusu üzerinde yapılan çalışma neticesinde kalkıştan, düşme anına kadar kritik safhalar UTC zamanına göre aşağıda sunulmaktadir;

- 05.36.12: 50’lik flap ayarıyla kalkışa hazır halde pist başında kuleden müsaade istemiştir.

- 05.37.36: Kule kalkışa müsaade etmiş ve sonrasında kalkış gerçekleşmiştir.

- 05.38.40: Sol ve sağ hücum açısı sensörleri arasında farklılık oluşmaya başlamıştir.

- 05.39.00: Sol ve sağ AoA sensörlerinden kokpite aktarılan veriler arasında yaklaşık $59^{\circ}$ ' lik bir farka ulaşmıştır.

- 05.39.30: Kulenin 34.000 feet irtifaya tırmanma talimatının ardından flaplar nötr durumuna alınmıştır.

- 05.39.39: MCAS ilk defa devreye girmiş ve uçağa burun aşağı komutunu vermiş. Pilotlar yaklaşık 40 kg'lık bir karşı kuvvet uygulayarak burnu kaldırmayı başarmış ve olumsuz durumu bertaraf etmiştir. 
- 05.40.22: Uçak tekrar MCAS kontrolünde burun aşağı pozisyonu almıştır. Bu s1rada EPGWS derin dalışın önlenmesi için burun yukarı (Pull up) uyarısı vermiştir.

- 05.40.38: Pilotlar ise burnu yukarı almak amacıyla elektrik trim sistemini devreye sokmuşlardır.

- 05.40.43: Elektrik trim sisteminin devre dışına alınmasından 5 saniye sonra MCAS tekrar devreye girerek uçağın burun aşağı pozisyona sokmuştur.

- 05.40.50: Kaptan ikinci pilota kuleyle irtibata geçerek uçakta bir uçuş kumanda sorunu yaşadıklarını ve 14.000 feete tırmanıp, irtifayı muhafaza edeceklerini bildirmesini talep etmiştir.

- 05.43.21: MCAS bir daha devreye girerek uçağın burnunun dikey vektörde negatif pozisyonda hareket ettirmiştir. Pilotlar yaklaşık 45 kg'lık bir kuvvetle lövyeyi çekerek burnu kaldırmaya çalışmışlar ancak burun açısının +0,50'den, -7,80’ye gelmesine engel olamamışlardır. Uçağın bu durumda yaklaşık 5000 feet/dakikalık alçalma oranı (Varyo) ile yere yaklaştığ 1 görülmektedir. Pilotlar 180 libreye yakın bir karşı tazyik ile burnu yuları kaldırmaya çalışsalar da başarılı olamamışlardır.

- 05.43.44: Uçak -400 burun açısı, 500 knot (Yaklaşık 926 km/saat) sürat ve 33.000 feet/dakikalık alçalma oranı ile yere çarpmıştır

Uçuşun genel seyrinde oto-pilot ve pilotların karşılıklı kumandalarına yönelik hususlar aşağıda sunulmaktadır:

- 05.39.00: Sol ve sağ AoA sensörlerinden kokpite aktarılan veriler arasında oluşan yaklaşık 59' lik fark 05:43:30'a kadar devam etmiştir. Aynı zaman aralığında sol yoke'ta titreşim aktif olarak kalmıştır.

- 05.40.50: Kaptanın 14.000 feet irtifaya tırmanma isteğine kule olumlu cevap vermiş ancak bu isteklerini yerine getirmeleri mümkün olamamış ve uçağın arzu edilen uçuş rotasına yerleşmesi sağlanamamıştır. Bunun üzerine kaptan kuleden kalktıkları piste tekrar dönmek için müsaade istemiştir.

- 05.43.21: Uçağın bu durumda yaklaşık 5000 feet/dakikalık alçalma oranı (Varyo) ile yere yaklaştığı görülmektedir. Pilotlar 180 libreye yakın bir karşı tazyik ile burnu yuları kaldırmaya çalışsalar da başarılı olamamışlardır [17].

\section{DEĞERLENDİRME VE BULGULAR}

Yolcu uçakları ömür devri boyunca yaklaşık 120.000-130.000 saat arasında uçuş yapmaktadır [18]. Yaklaşık 8983 uçuş saatine sahip PQ-LQP çağrı kodlu Endonezya uçağının ve yaklaşık 1330 uçuş saatine sahip ET-AWJ çağrı kodlu Etiyopya uçaklarının yeni uçaklar olduğunu söylemek mümkündür. Uçakların yeni olması, bakımlarının zamanında gerçekleştirilmesi, pilotların tecrübeli ve meteorolojik şartların uygun ol- 
ması, kazaların meydana gelmesinde üretim aşamasına yönelik soruların oluşmasına sebebiyet vermiştir.

\subsection{B-737 Max Üretim Süreci}

1960’lı yıllar tüm dünyada yolcu talebinin arttığ 1 yıllar olarak bilinmektedir. Lufthansa gibi havayolu işletmecileri Boeing' ten daha çok yolcuyu daha uzak menzile taşıyacak uçaklar talep etmişlerdir. O dönem Boeing'in 106 yolcu kapasiteli kuyruk bölümünde 3 adet düşük güç üreten motor bulunan 727 tipi uçakları mevcuttur. Boeing 737 uçağının üretim süreci, kuyrukta bulunan motorların daha fazla güç üretecek şekilde büyültülerek kanat altlarına taşınması ile başlamıştır. Böylece yolcu kapasitesi 124 'e çıkarılmıştır. Havayolu taşımacılığında bir yolcunun bile önemli olduğu düşünüldüğünde bu büyük bir atılım olarak görülebilir.

B-737-100 uçaklarının gövde ve motorlarında yapılan değişikliklerden sonra, 21 Aralık 1967 tarihinde ABD Federal Havacılık Dairesi (Federal Aviation AdministrationFAA) tarafindan sertifiye edilen ilk B-737-200 uçağ1, yolculu uçuşunu 28 Nisan 1968 tarihinde Chicago'dan Michigan Grand Rapids'e gerçekleştirilmiştir. Günümüze kadar üretilegelen Boeing 737 ailesi uçakları B-737-100'ün üzerine inşa edilmiştir [19]. 1960’lı yıllardan günümüze kadar B-737 uçağının, değişik versiyonlarından 10.000 adet üretilmiştir. Boeing tarafından yapılan açıklamada Washington, Renton tesislerinde 737 serisi uçakların üretiminin 2019 yılı için aylık 52'den 57'ye çıkarıldı̆̆ı bildirilmiştir. Endonezya ve Etiyopya kazalarından sonra, B-737 Max serisi uçakların üretimi durdurulmuş; ancak $-600,-700,-800$ ve -900 versiyonlarının üretimi durdurulmamıştır [20].

Diğer taraftan Airbus firması da Avrupa Kıtası'nda öncü bir hava aracı üretim firması olarak karşımıza çıkmaktadır. Airbus ve Boeing ticari havayolu uçağı üretiminde ana rolü üstlenen iki imalatçıdır. Her iki üretici gökyüzündeki uçakların yaklaşık \%81'ini üretmişlerdir [21]. Şekil 4'te 2008-2018 yıllar arasındaki yolcu uçağı üretim dağılımından görüleceği üzere geriye kalan \%19'luk kısım, Brezilya menşeili Embraer, Kanada menşeili Bombardier, Fransa menşeili ATR gibi üreticiler ve aralarında Rus-Çin ortak yapımı Comac şirketinin de bulunduğu diğerleri arasında paylaşılmaktadır.

Doğal olarak Boeing ve Airbus zorlu bir rekabet içerisinde üretim yapmaktadırlar. Bir firmanın ürettiği bir modele rakibi, pazardaki gücünü kaybetmemek adına başka bir model ile yanıt vermektedir. Örneğin büyük gövdeli Airbus A380 uçağ1, B-747 uçağına bir rakip olarak üretilmiştir. B-737 Max uçağı için de benzer bir durum söz konusudur. B-737 Max, Airbus'1n A319/A320 ve A321 ailesinde daha efektif ve daha büyük çaplı bir motor kullanmaya başlamasının ardından, Boeing’in 737 NG uçağından değiştirilerek daha büyük bir motorla üretilmesi sonucunu ortaya çıkartmıştır. Bu çerçevede B-737 Max uçağının, Neo motorları ile faaliyet gösteren Airbus A320 ailesi 


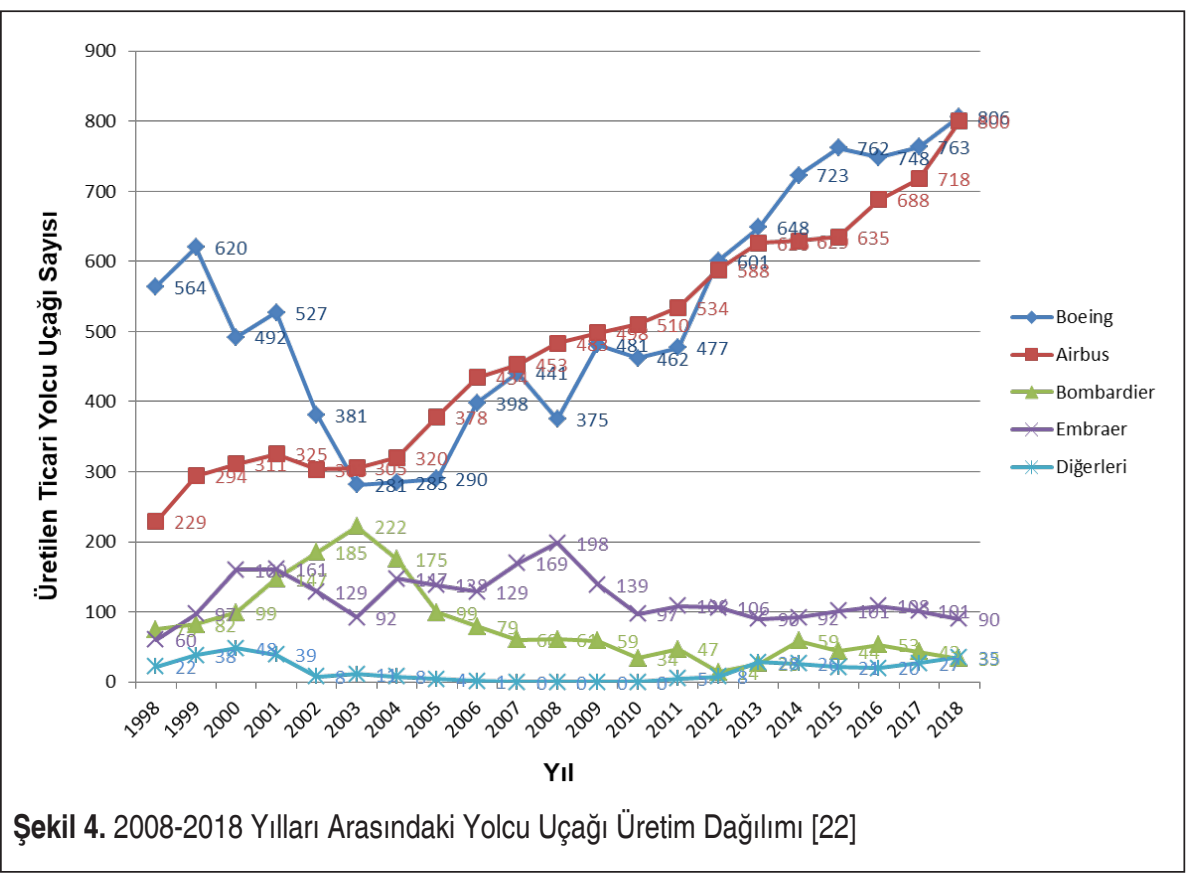

uçaklarına bir cevap olarak üretildiğini söylemek mümkündür. Ancak, daha önce ifade edildiği gibi, bu hızlı dönüşüm beraberinde yeterince olgunlaşmamış teknolojilerin hava araçlarına uyarlanmasındaki riski de beraberinde getirmiştir [5].

\subsection{Aerodinamik Kararsızlık ve Havada Tutunamama (Perdövites/Stall)}

Her uçağın tasarımına göre bir havada tutunma sürati vardır. Bu sürat, uçak kanatlarının geometrisi ve üzerinde yer alan flap, slat gibi donanımlara bağlı olarak uçabileceği minimum sürattir. Tutunma süratinden daha düşük bir değerde, seyir halindeki uçağın kanadında oluşan kaldırma kuvvetinin, uçağın ağırlığını karşılaması mümkün olmamaktadır. Bu duruma stall ya da perdövites adı verilmektedir. Stall ya çok düşük bir hız ya da kanadın hava akışına göre kritik hücum açısını aşması nedeniyle kanadın kaldırma etkisinin kaybolma durumu olarak özetlenebilmektedir. Şekil 5 'te gösterildiği üzere yüksek hücum açısında, kanadın üst kısmında hava girdapları oluşmaktadır. Oysa kararlı bir uçuş için alttaki şekilde olduğu gibi kanadın alt ve üst kısmında profil geometrisini takip eden hava akımının meydana gelmesi arzu edilmektedir.

Stall, diğer adı ile perdövites uçağın düşmesine sebebiyet vermektedir. Tutunamama durumundan kurtularak kararlı uçuşa tekrar dönmek için Tablo 1'de yer alan işlem basamaklarının uygulanması gerekmektedir. 


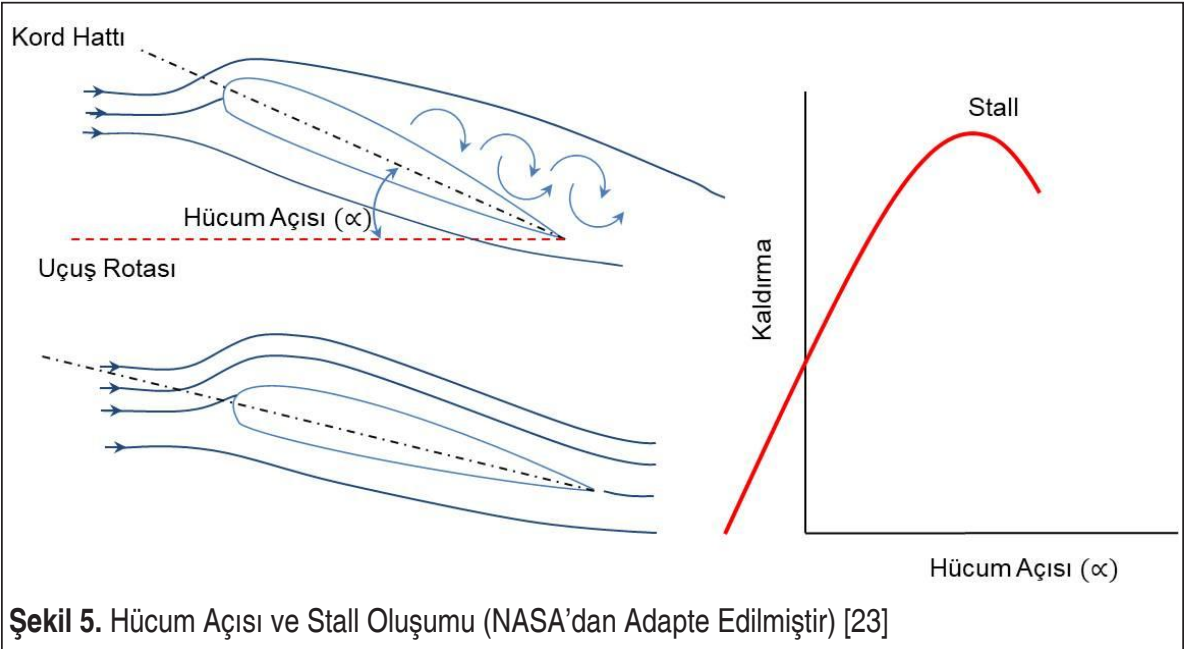

Tablo 1. Perdövitesten Kurtulma Usulleri [24]

\begin{tabular}{|l|l|}
\hline \multicolumn{2}{|c|}{ Perdövitesten Kurtulma Usulleri } \\
\hline \multicolumn{1}{|c|}{ Durum } & \multicolumn{1}{c|}{ Komut } \\
\hline 1. Kanat düzenleyici ya da otopilot & 1. Devreden çıkarınız. \\
\hline $\begin{array}{l}\text { 2.a. Burun aşağı verme } \\
\text { b. Burun açısını ayarlama }\end{array}$ & $\begin{array}{l}\text { 2.a.Tutunamama emareleri ortadan kalkıncaya kadar devam } \\
\text { ediniz. } \\
\text { b. İntiyaç duyulduğu kadar yapınız. }\end{array}$ \\
\hline 3. Yatış açısı & 3. Düz (Ufki) uçuşa geçiniz. \\
\hline 4. Güç / Takat & 4. İtiyaç duyulduğu kadar gaz açınız. \\
\hline 5. Hız frenleri / bozucular & 5. Kapalı duruma alınız. \\
\hline 6. Uçuş rotası & 6. İtiyaç duyulan rotaya dönünüz. \\
\hline
\end{tabular}

\subsection{B-737 Max Uçağında Dikey Vektörde Aerodinamik Kararsızlık Oluşu- munun Sebepleri ve Boeing'in Buna Getirdiği Çözüm}

Aynı segmentteki uçaklar mukayese edildiğinde Boeing'in ürettiği uçakların Airbus'a oranla yere daha yakın olduğu (Ground Clearance) bilinmektedir. B-737 Max modeline, B-737 NG modelindeki motorlardan daha büyük çaplı motorlar yerleştirilmesi zaten yere yakın olan motor dış çerçevesinin yere daha çok yakınlaşması sonucunu beraberinde getirmiştir. Boeing mühendisleri sorunu çözmek için, B-737 Max üzerindeki motoru kanat üzerinde daha yukarı ve daha öne monte etmişlerdir [25].

B-737 Max programının başından itibaren Boeing’in üst düzey yöneticilerinin, yarım 
asırlık eski 737 uçak gövdesini daha büyük motorlarla güçlendirmenin uçağın aerodinamik ve operasyonel performansını temelden değiştireceğini bildikleri ön görülmektedir. Şekil 6'da gösterildiği üzere, Boeing'in Seattle tesislerinde 2012 yılında yapılan testler yeni motorların uçuşta anormal halde yükselme eğilimi ve sonuçta yüksek hücum açısı nedeniyle tutunamamaya sebebiyet veren aerodinamik dengesizlik yarattığını ortaya çıkarmıştır.

Yapılan testlerde, yüksek hücum açılarında, uçağın burnu gökyüzüne doğrultulduğunda, motorların adeta bir kanat gibi, ek bir kaldırma sağlayarak uçağı daha da yüksek bir hücum açısına zorladı̆̆ı gözlemlenmiştir.

Boeing, tutunamama sorununu Şekil 6'da yer alan dengeleyici kuvveti otomatik devreye sokan bir yazılımla (Manevra Karakteristiği Güçlendirme Sistemi (MKGS, Maneuvering Characteristics Augmentation System-MCAS) çözüm yoluna gitmiştir. Şekil 7'de gösterildiği üzere amaç, ani tutunamama durumuna karşı yatay dengeleyiciyi otomatik olarak harekete geçirerek irtifanın sürate çevrilmesini sağlamaktır. Böylece hız kazanımı ve havada tutunmanın sağlanması amaçlanmaktadır. Bu durum, pilotajda "irtifanın sürate çevrilmesi" olarak isimlendirilmekte ve havada tutunamama durumunda bir acil durum manevrası olarak kullanılmaktadır.

Sistem mimarisi açısından bakıldığında buradaki sorun B-737 Max’ın üzerindeki iki AoA sensörünün bir tanesinden dâhi burnun aşırı kalktığına dair veri alınması durumunda MCAS'in bu sinyali doğru kabul ederek uçağın kumandasını devralması ve dalışa geçirmesidir. Pilotların MCAS'i devreden çıkarmaya yönelik müdahalelerine rağmen, yazılımdan dolayı uçak bütünüyle pilotlar tarafından kumanda edilebilir hale geçmemekte ve kısmi olarak dahi olsa otopilot kontrolünde kalmaktadır. Bir anlamda uçak, pilotların müdahalesine rağmen otopilottan çıkmamaktadır [27].

Uçakların aviyonik tasarımı, pilotların mimari hakkında bilgi sahibi olmalarını zorunlu kılmamaktadır. Uçak tasarımında kullanılan mühendislik bilgileri bir arayüz

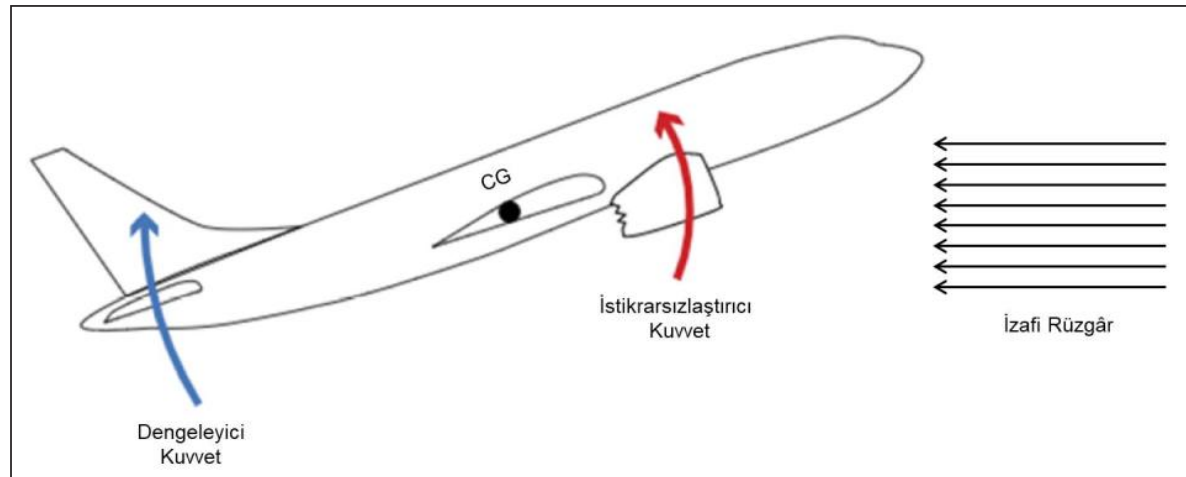

Şekil 6. B-737 Max Uçak Motorlarının Öne Taşınması Nedeniyle Oluşan Kararsızlık [26] 


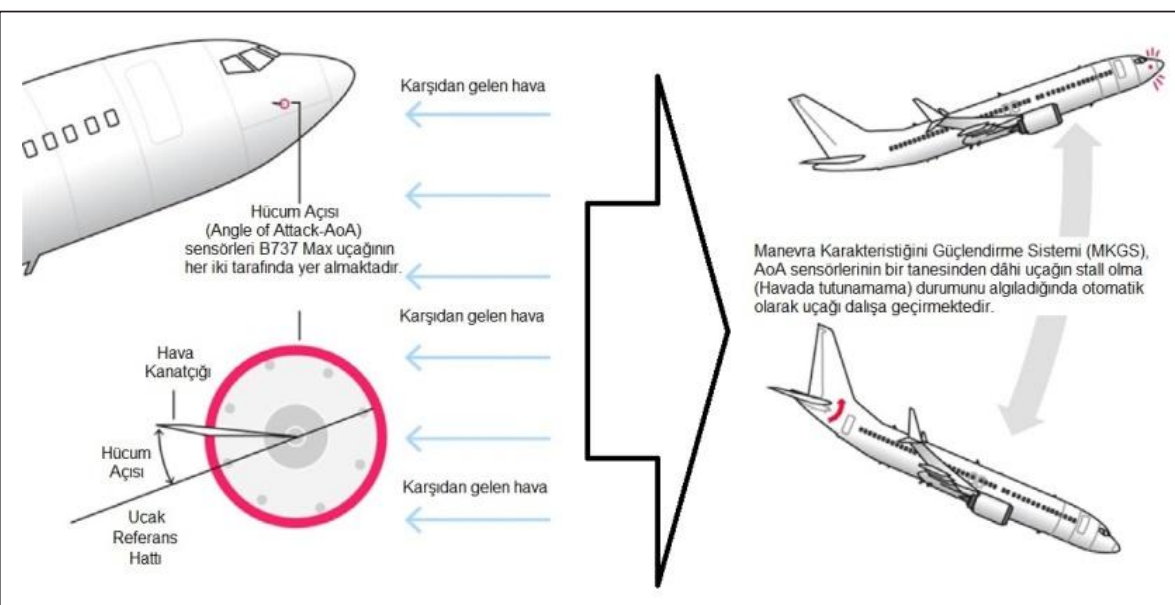

Şekil 7. Hücum Açısı Sensörleri ve MCAS Çalışma Sistematiği [1]

aracılığıyla sistemlerin kullanıcısı olan ilgili personele aktarılmaktadır. Bu nedenle, uçakta arka planda çalışan sistemlerden pilotların haberdar olmalarına gerek yoktur. Personelin, uçuş emniyetini ön planda tutacak şekilde, arayüzleri uygun şekilde kullanmaları yeterli kabul edilmektedir. Ancak MCAS için durumun çok farklı olduğu düşünülmektedir. MCAS, pilotların uçuşa konsantrasyonlarında fayda sağlayacak ve uçuş emniyetini artıracak bir sistem olarak tasarlanmışken, sadece bir AoA sensörü verisinden yola çıkılarak MCAS' in devreye girmesi sebebiyle uçuş emniyetini tehlikeye düşüren bir sistem haline dönüşmüştür. Her iki kazada da MCAS' in aralıklı olarak otopilot kontrolü ile "yere çarpana kadar" uçakları dalış pozisyonunda tuttuğu gözlemlenmektedir [16,17].

Yapılan risk değerlendirmesinde, AoA sensörlerinin hatalı veri üretmesi nadir gerçekleșen bir olay ve bu nedenle MCAS'in gelen hatalı veriyi esas alarak devreye girme olasılığının düşük olduğu düşünülebilir ancak

MCAS'e bağlı kazanın şiddetinin yüksek olması sebebiyle risk indeksi çok yüksek bir durum olarak gözlemlenmektedir [28].

\subsection{MCAS ile İlgili Pilotlara Verilen Eğitim}

Test uçuşlarında söz konusu sorunun baş göstermesi sonucunda Boeing yukarıda belirtildiği şekilde otomatik olarak devreye giren MCAS' i bir yazılım desteği ile beraber uçaklara uyarlamıştır. Uçaklara uyarlanan yeni sistemlerin pilot ve bakım personeli gibi ilgili personele eğitimlerinin verilmesi zorunluluktur. American Airlines şirketinde görev yapan pilotların kurduğu Birleşik Pilotlar Derneği (Allied Pilots Association-APA) tarafından MCAS için sadece 1 saatlik tablet üzerinden eğitim verildiği açıklaması yapılmıştır [29]. 
B-737 Max uçaklarını filolarında kullanmak üzere satın alan firmalar kendi uçuş personeline MCAS' in kullanımının yaklaşık bir saatlik süre içerisinde tablet destekli kısa bir eğitimle veriliyor olmasını bir tanıtım ve reklam vasıtası olarak kullanmıştır. FAA ise Boeing' ten MCAS' e yönelik özel bir detaylı çalışma istememiştir. Çünkü havacılık kuralları gereği sıfırdan bir uçak üretimi sürecindeki sertifikasyon süreçlerinin, aynı uçağın alt modellerinin üretilmesinde baştan sona kadar tekrar edilmesine gerek duyulmamaktadır. Burada re-sertifikasyon süreci işletilmekte olup, uçak üreticileri sadece yeni modeldeki farkl11ıkları ilgili havacılık otoritesine bildirmektedir. FAA sıfırdan uçak üretimi için tip sertifikasyonu ve üretilmiş uçağın modellerinin üretimi için re-sertikasyon süreçlerinde bazı durumlarda uçak üreticisi firmalar bünyesindeki Atanmış Mühendislik Temsilcileri (AMT, Designated Engineering RepresentativeDER) aracılığıyla uçağın uçuş emniyetine uygun olarak üretilip üretilmediklerini kontrol etmektedir. DER üyeleri uçak üretici firmanın personeli olup,

FAA mühendisleri tarafından yapılması gereken tüm kontrolleri yapmakla mükelleftirler [30]. B-737 Max uçakları re-sertifikasyon sürecinde FAA, MCAS' in detaylı bilgilerinin istenmemesini 737 Max uçağının, 737 NG'den dönüştürülen bir uçak olmasına bağlanmaktadır.

\section{SONUÇ}

Arka arkaya yaşanan B-737 Max uçak kazaları, toplamda 346 insanın hayatını kaybettiği dünya havacılığında önemli etkilere sahip olan kazalar olarak yer edinecektir. Kaza sonrası araştırmaların, FAA ile Boeing'in arasındaki organizasyonel bağlantılara odaklanması, söz konusu kazaların uzun vadede birçok tartışmalara yol açacağı izlenimini uyandırmaktadır.

\section{1 İdari ve Eğitimsel Konular}

Boeing personeli olan ancak FAA adına çalışma yapan DER personeli, yeni model uçak üzerindeki önemli değişiklikleri test edip onaylama yetkisine sahiptir [31]. Bu durumun personelin doğru kararlar veremiyor olmasına yol açabileceğine dair tartışmalar devam etmektedir [32]. Çin havacılık otoritesi Civil Aviation Administration of China (CAAC), Çin uçak üretim şirketi Comac'ın ARJ21 uçağının uçuşa elverişlilik işlemleri sırasında benzer bir şekilde Aday Atanmış Mühendislik Temsilcileri (AAMT, Candidate Designated Engineering Representatives-CDER) personelinden istifade etmiş ancak bu personelin yetkilerini sadece bazı dokümanların hazırlanması ile kısıtlamıştır. Söz konusu süreçte uçuşa elverişlilik işlemlerinde CAAC, kendi personelini doğrudan görevlendirmiştir [33].

Yeni tip ve yeni model uçakların sisteme alınması durumunda, verilmesi gereken eğitimlerin risk tabanlı analizler ile belirlenmesi gerekmektedir [34]. Risk tabanlı bir 
modelden yola çıkılması durumunda pilot ve bakım personeli gibi uçuş emniyetini doğrudan etkileyen personelin eğitim süreleri, ortamı ve eğitim yardımcılarının neler olacağı net olarak belirlenmiş olacaktır.

\subsection{Havacılık Mühendisliği Çerçevesinde Öneriler}

Boeing'in karmaşık bir aerodinamik kararsızlık sorununu basite indirgeyerek bir yazılım hatası olarak gösterme çabası içerisinde olduğu gözlemlenmektedir. Oysa havacılık gibi teknoloji yoğun proje yönetimlerinde sadece yazılımsal çözümlemeler yapılmaması gerektiği, B-737 Max vakası üzerinden ifade edilmektedir [35].

B-737 Max uçakları üzerinde iki adet AoA sensörü bulunmakta ve bu sensörlerden bir tanesinin burnun aşırı yükseldiğine dair veri aktarması durumunda uçak otopilot kontrolünde dalışa geçmektedir. Boeing' in aynı segmentte yer alan Airbus A320 ile mukayesesinde benzer tip uçak olan A320 uçağında 2 adet sol tarafta aynı yatay düzlemde ve 1 tane sağ tarafta olmak üzere 3 adet AoA sensörü bulunmaktadır [36]. Airbus uçağındaki 3 adet sensörden alınan verilerde bir oylama prensibi (Voting principle) uygulanmaktadır. Bu prensip gereğince, hangi iki sensörün verisi birbirine uyuyorsa diğer veri saf dışı bırakılmaktadır. Bir anlamda otopilot AoA sensörlerinden alınan verilere göre, hareket tarzına oy çokluğuyla karar vermektedir. Konunun hassasiyetine binaen, Airbus A320 uçağına ait Uçuş Mürettebatı Operasyonel El Kitabı'nda (Flight Crew Operational Manual-FCOM); "Yüksek hücum açısı koruması diğer korumaların hepsinden daha önemlidir." ifadesi yer almaktadır [37]. Airbus A320'deki AoA sensör mimarisi ve algoritmasının uçuş emniyetini yükselttiği gözlemlenmektedir.

Bu çerçevede sadece B-737 Max uçağı kazaları değil 25 Şubat 2009 tarihinde Hollanda Schipol Havaalanı'nda son yaklaşmada meydana gelen THY'nin 1951 sefer sayılı B-737-800 uçağının yaşadığı kazanın da incelenmesi gerekmektedir. Söz konusu uçakta da iki adet AoA'dan sadece bir tanesinin sağladığı veri ile hareket edilmiştir.

\subsection{Sertifikasyon}

Hava araçları sertifikasyonunun en temel amacı can ve mal güvenliğinin sağlanmasıdır [38]. Bir hava aracının uçuşa elverişlilik sertifikasyonu sürecinde Tip Sertifikası'nın verilmesi en önemli basamaklardan birisi olarak değerlendirilmektedir. Sertifikasyon işlemlerinin hayata geçirilmesi aşamasında, otorite tarafindan gerçekleştirilen kural tabanlı sertifikasyon işlemlerinde, aynı tipin bir önceki modeli ile bir sonraki modeli arasındaki farklı sistemlerin neler olduğunun ve kaç saatlik eğitimlerle yeni sistemlerin ilgili personele veriliyor olduğuna dair bilginin havacılık otoritesine bildirilmesi yeterli olmaktadır. Oysa uçuşa elverişlilik süreci sivil uçakların, motor ve pervanelerinin havacılık otoriteleri tarafindan sertifiye edilmelerini içerecek kapsamlı bir süreçtir. 
Tip sertifikasına sahip bir uçağın, yeni bir modelinin re-sertifikasyonu aşamasında özellikle uçaklara uyarlanan yeni teknolojilerin kullanımı son derece önemlidir. Elbette her yeni teknolojinin amacı havacılık emniyetini artırmak ve personelin daha rahat çalışmasını sağlamaktır. Ancak diğer taraftan; uçağın aerodinamik kararlılığını doğrudan etkileyen sistemlerin uyarlandığı yeni bir modelin, re-sertifikasyon sürecinde tehlike analizlerinin yapılmış olması önem arz etmektedir. Bu nedenle, özellikle aerodinamik yapıyı etkileyen yeni sistemlerle donatılan hava taşıtlarının uçuşa elverişlilik onaylarının verilmesi sürecinde risk tabanlı sertifikasyon işlemlerinin uygulanması uygun olacaktır.

\section{KAYNAKÇA}

1. Sgobba, T. 2019. "B-737 MAX and the Crach of the Regulatory System". Journal of Safety Engineering. 6, 4, 299-303.

2. Aksoy, C., Dursun, Ö. O. 2018. "A General Overview Of The Development Of The Civil Aviation Sector in Turkey”. Electronic Journal Of Social Sciences. 17, 7, 1060-1076.

3. Doucet, G. 2019. "Outer space SARPs: A Mechanism for Implementation of Space Safety." The Journal of Space Safety Engineering. 6, 2, 145-149.

4. Nancy, L., Wilkinson, C., Fleming, C., Thomas, J., Tracy, I. 2014. A Comparison of STPA and the ARP 4761 Safety Assesment Process. MIT PSAS Technical Report, Rev.1, MIT, Massachusetts.

5. ICAO. 2018. "News and Developments From The International Civil Aviation Organization". Strengthening Regional Safety Oversight. 3, 2, 11.

6. Kenaroğlu, Y. 2010. "Hava Araçlarının Uçuşa Elverişlilik Sertifikasyonu". Mühendis ve Makina. 52, 614, 16-28.

7. Saracyakupoglu, T. 2020. "The Adverse Effects of Implementation of the Novel Systems in the Aviation Industry in Pursuit of Maneuvering Characteristics Augmentation System (MCAS)". Journal of Critical Reviews. 7, 11, 2530-2538.

8. FAA. 2017. Type Certification. U.S. Department of Transportation, Order $8110.4 \mathrm{C}$ Chg 6. https://www.faa.gov/documentLibrary/media/Order/FAA_Order_8110_4C_chg_6_ only.pdf (İnternet Erişimi 14.08.2020).

9. Han S.M., Lee S.M., Yim H.B., Seong P.H. 2017. "Development of Nuclear Safety Culture Evaluation Method for an Operation Team Based on the Probabilistic Approach". Annals of Nuclear Energy. 111, 317-328.

10. Campbell, R., Bagshaw, M. 2002. Human Performance and Limitations in Aviation. ISBN 0-632-05965-6, Blackwell Science, Oxford.

11. ICAO. 2019. State of Global Aviation Safety. Safety Report. https://www.icao.int/safety/ Documents/ICAO_SR_2019_final_web.pdf (İnternet Erişimi 14.08.2020).

12. ICAO. 2001. International Standards And Recommended Practices - Annex 13, Aircraft 
Accident and Incident Investigation. https:/www.icao.int/safety/airnavigation/AIG/ Pages/Documents.aspx (İnternet Erişimi 14.08.2020).

13. Saraçyakupoğlu, T. 2020. Emniyet İrtifasından Bilgiler: Genel Havacılık, Üretim ve Bakım Süreçleri. ISBN: 978-625-402-030-8, Nobel Akademik Yayıncılık, Ankara.

14. Çetingüç, M. 2018. Havacılık ve Uzay Psikolojisi. ISBN: 978-605-320-495-4, Nobel Akademik Yayıncılık, Ankara.

15. Wendel, W. B. 2019. "Technological Solutions to Human Error and How They Can Kill You: Understanding the Boeing 737-Max Products Liability Litigation”. Journal of Air Law and Commerce. 84,3, 1-43.

16. KNKT. 2019. Aircraft Accident Investigation Report. Final Report. KNKT.18.10.35.04. Komite Nasional Keselamatan Transportasi. Indonesia.

17. ECAA. 2019. Aircraft Accident Investigation Bureau Interim Report. Interim Investigation Report. AI-01/16. Ministry of Transport. Ethiopia.

18 Bye, G. 2017. "Cheaper, Lighter, Quieter: The Electrification of Flight Is at Hand", https://spectrum.ieee.org/aerospace/aviation/cheaper-lighter-quieter-the-electrificationof-flight-is-at-hand, son erişim tarihi: 14.08.2020.

19. Hill, M. L. 2002. Boeing 737. ISBN: 186126404 6, The Crowood Press, Wiltshire.

20. Zang, B. 2019. "Here's how much Boeing is estimated to make on each 737 Max 8 plane", https://www.businessinsider.com/boeing-737-max-profit-moodys-2019-3, son erişim tarihi: 14.08.2020.

21. IATA. 2019. Airline Maintenance Cost Executive Commentary Report. https://www.iata. org/contentassets/bf8ca67c8bcd4358b3d004b0d6d0916f/mctg-fy2018-report-public. pdf, son erişim tarihi: 14.08.2020.

22. Mazarenau, E. 2019. Number of jets added to the global aircraft fleet from 1998 to 2018, by manufacturer, https://www.statista.com/statistics/622779/number-of-jets-delivered-global-aircraft-fleet-by-manufacturer/ son erişim tarihi: 14.08.2020.

23. NASA. 2020. "Inclination of Lift" https:/Www.grc.nasa.gov/WWW/K-12/airplane/incline.html,son erişim tarihi: 14.08.2020.

24. FAA. 2004. Airplane Flying Handbook: FAA-H-8083-3B, Chapter 4: Maintaining Aircraft Control:Upset Prevention and Recovery Training. https://www.faa.gov/regulations_policies/handbooks_manuals/aviation/airplane_handbook/media/06_afh_ch4.pdf, son erişim tarihi: 14.08.2020.

25. Palmer, C. 2019. "The Boeing 737 Max Saga: Automating Failure". Engineering, 6, 1, 2-3.

26. Josefson, A., Browne J.C., Sinderson K.M., Hollander A.D., Fee J.M. 2020. "In Re: Boeing Company Aircraft Securities Litigation", Consolidated Class Action Complaint”. Case No. 1:19-cv-02394, Bernstein Litowitz Berger and Grossman LLP, Chicago.

27. Scott, A., Foo , W., M. Johnson, E. 2019. Change to 737 MAX controls may have 
imperiled planes, experts say, https://graphics.reuters.com/ETHIOPIA-AIRLINE-CONTROLS/0100916V1NZ/index.html, son erişim tarihi: 14.08.2020.

28. Arandas, I., Bogdane, R., Gorbacovs, O., Sestakovs, V. 2018. "Development of a model for assessing the level of flight safety in an airline using concept of risk". Procedia Computer Science. 149, 365-374.

29. Levin, B. 2019. "Boeing Trained 737 Max Pilots on iPads to Save Cash". https://www. vanityfair.com/news/2019/03/boeing-trained-737-max-pilots-on-ipads-to-save-cash/ amp (İnternet Erişimi 14.08.2020).

30. FAA. 2017. Designated Engineering Representative (DER) Handbook. Report No: 8110. 37 F. Federal Aviation Administration. Washington D.C.

31. Florio, F. 2016. Airworthiness: An Introduction to Aircraft Certification and Operations, ISBN: 978-0-08-100888-1, Butterworth-Heinemann, Elsevier, Oxford.

32. Borfitz, M. 2020. "What FAA Delegation Does-How And Why?" http://jdasolutions. aero/blog/what-faa-delegation-does-how-and-why, son erişim tarihi: 14.08.2020.

33. Kun, Y., Cunxi, L. 2011. "Comparison on the Ways of Airworthiness Management of Civil Aircraft Design Organization”. Procedia Engineering, 17, 388-395.

34. Leveson, G. N. 2018. "Safety Analysis in Early Concept Development and Requirements Generation”. 28th annual INCOSE International Symposium .07-12 July 2018, Washington D.C.

35. Narayanan, S., Balasubramanian, S., M. Swaminathan, J., Zhang, Y. 2019. "Managing uncertain tasks in technology-intensive project environments: A multi-method study of task closure and capacity management decisions", Journal of Operations Management. 66,1, 260-280.

36. Airbus. 2020. Aircraft Characteristics Airport and Maintenance Planning. https://www. airbus.com/content/dam/corporate-topics/publications/backgrounders/techdata/aircraft_characteristics/Airbus-Commercial-Aircraft-AC-A320.pdf, son erişim tarihi: 14.08.2020.

37. Airbus. 2018. A318/A319/A320/A321 Flight Crew Operating Manual. Toulouse.

38. Yanlei, G., Yanpei, Z. 2011. "Airworthiness Management of CFM56 Products in FAA and EASA”. Procedia Engineering. 17, 588-594. 